\title{
Intrathecal Treatment With 6-Hydroxydopamine or 5,7-Dihydroxytryptamine Blocks the Antinociception Induced by Endomorphin-1 and Endomorphin-2 Given Intracerebroventricularly in the Mouse
}

\author{
Kuei-chun Hung ${ }^{1}$, Hsiang-en $\mathrm{Wu}^{1}$, Hirokazu Mizoguchi ${ }^{2}$, Randy Leitermann ${ }^{1}$, and Leon F. Tseng ${ }^{1, *}$ \\ ${ }^{1}$ Department of Anesthesiology, Medical College of Wisconsin, \\ 8701 Watertown Plank Road, Milwaukee, Wisconsin 53226, USA \\ ${ }^{2}$ Department of Physiology and Anatomy, Tohoku Pharmaceutical University, \\ 4-4-1 Komatsushima, Aoba-ku, Sendai 981-8558, Japan
}

Received March 31, 2003; Accepted August 22, 2003

\begin{abstract}
The involvement of spinopetal noradrenergic and serotonergic systems in antinociception induced by endomorphin-1 (EM-1) and endomorphin-2 (EM-2) given supraspinally or spinally were investigated in male CD-1 mice. Groups of mice were pretreated intrathecally (i.t.) with 6-hydroxydopamine (6-OHDA, $20 \mu \mathrm{g}$ ) or 5,7-dihydroxytryptamine (5,7-DHT, $50 \mu \mathrm{g})$ for 3 days before intracerebroventricular (i.c.v.) or i.t. injection of different doses of EM-1 or EM-2, and the tail-flick response was measured for antinociceptive effects. I.t. pretreatment with 6-OHDA for 3 days, which markedly depleted noradrenaline (NA) contents by more than $90 \%$, but not serotonin (5-HT) in the spinal cord, completely abolished the antinociception induced by i.c.v.-administered EM-1 or EM-2. Intrathecal pretreatment with 5,7-DHT for 3 days, which markedly reduced 5 -HT contents by more than $92 \%$, but only reduced NA by $14-25 \%$ in the spinal cord, also markedly attenuated the antinociception induced by i.c.v.-administered EM-1 or EM-2. However, the antinociception induced by i.t.-administered EM-1 or EM-2 was not affected in either 6-OHDA or 5,7-DHT pretreated mice. It is concluded that NA and 5-HT in the spinal cord are involved in the antinociception induced by supraspinally, but not spinally administered EM-1 and EM-2.
\end{abstract}

Keywords: endomorphin, noradrenaline, serotonin, 6-hydroxydopamine, 5,7-dihydroxytryptamine

\section{Introduction}

Endomorphin-1 (EM-1) and endomorphin-2 (EM-2) are two tetrapeptides isolated from the bovine frontal cortex (1) and human brain (2) and are proposed to be the endogenous ligands for $\mu$-opioid receptors. Receptor-binding assays and immunocytochemical studies reveal that EM-1 and EM-2 are highly selective for $\mu$-opioid receptors and are localized in the regions of the brain and the spinal cord that are abundant in $\mu$-opioid receptors $(3-10)$. The release of EM-2 from the dorsal horn of the spinal cord by electrical stimulation and the inhibition of the electrical activity of spinal substantia

*Corresponding author. FAX: +1-414-456-6507

E-mail: ltseng@mcw.edu gelatinosa neurons or rostral ventrolateral medulla in vitro by EM-1 and EM-2 have been demonstrated (3, $10-12$ ). Like other $\mu$-opioid receptor agonists, EM- 1 or EM-2 activates $\mu$-opioid receptors mediated G-protein activation only in wild type mice, but not in $\mu$-opioid receptor knockout mice (13). Intracerebroventricular (i.c.v.) or intrathecal (i.t.) injection of EM-1 or EM-2 produces potent antinociception that is selectively blocked by $\mu$-opioid receptor antagonists, naloxone, $\beta$ funaltrexamine, or CTOP (D-Phe-Cys-Tyr-D-Trp-OrnThr-Pen-Thr-NH $\left.\mathrm{N}_{2}\right)(1,14-16)$. The antinociception induced by EM-1 or EM-2 is significantly attenuated in heterozygous knockout mice and virtually abolished in homozygous knockout mice (13). These findings clearly support the notion that EM-1 and EM-2 are indeed 
endogenous opioid ligands and the antinociception induced by these two peptides are mediated by the stimulation of $\mu$-opioid receptors $(17,18)$.

The antinociception induced by $\mu$-opioid agonists such as morphine or DAMGO (D-Ala ${ }^{2}-N$-methyl-phe ${ }^{4}$ Gly-ol ${ }^{5}$ ) given i.c.v. is mediated by the activation of spinopetal noradrenergic and serotonergic systems to release noradrenaline (NA) and serotonin (5-hydroxytryptamine, 5-HT). The released noradrenaline and 5-HT subsequently act on $\alpha_{2}$-adrenoceptors and 5-HT receptors, respectively, in the spinal cord to produce antinociception. This view for the antinociception of morphine is supported by the findings that depletion of NA and 5-HT in the spinal cord induced by i.t. pretreatment with 6-hydroxydopamine (6-OHDA) and 5,7-dihydroxytryptamine (5,7-DHT), respectively, attenuates the antinociception induced by morphine administered supraspinally $(19-22)$. Also the blockade of the $\alpha_{2}$-adrenoceptor and 5-HT receptors in the spinal cord by i.t. treatment with yohimbine and methysergide blocks the antinociception induced by morphine given supraspinally (23). Since EM-1 and EM-2 are two endogenous ligands selectively for $\mu$-opioid receptors, the neuronal mechanisms involved in activation of the descending system to produce antinociception will be expected to be similar to that of morphine. The present study was then designed to determine the effects of i.t. pretreatment with 6-OHDA and 5,7-DHT to deplete NA and 5-HT, respectively, on the antinociception induced by supraspinally administered EM-1 and EM-2.

\section{Materials and Methods}

\section{Animals}

Male CD-1 mice (Charles River Breeding Laboratory, Wilmington, MA), weighing $25-30 \mathrm{~g}$ were used. Animals were housed five per group in a room maintained at $22 \pm 0.5^{\circ} \mathrm{C}$ with an alternating 12-h light-dark cycle. Food and water were available ad libitum. Animals were used only once.

\section{Drugs}

EM-1 (Tyr-Pro-Trp-Phe-NH ${ }_{2}$ ) and EM-2 (Tyr-ProPhe-Phe- $\mathrm{NH}_{2}$ ) were purchased from Calbiochem Corp. (La Jolla, CA, USA). The peptides were dissolved in sterile saline solution $(0.9 \% \mathrm{NaCl}$ solution $)$ containing $10 \%$ hydroxypropyl- $\beta$-cyclodextrin for i.c.v injection. 6-OHDA and 5,7-DHT (Sigma Chemical Company, St. Louis, MO, USA) were dissolved in $0.9 \%$ sterile saline containing $1 \mathrm{mg} / \mathrm{ml}(0.1 \%)$ ascorbic acid (Sigma Chemical Co.) to prevent them from being oxidized. Desipramine (Sigma Chemical Co.) was dissolved in $0.9 \%$ saline.

\section{Assessment of the antinociceptive response}

The antinociceptive response was assessed with the thermal tail-flick test (24). Mice were gently held with the tail positioned in the tail-flick apparatus (Model TF6; EMDIE Instrument Co., Maidens, VA, USA) for radiant heat stimulation of the dorsal surface of the tail. The intensity of the heat stimulus was adjusted to cause the animal to flick its tail within 3 to $4 \mathrm{~s}$ as the baseline of the tail-flick latency. After measuring the latency, different groups of mice were injected i.c.v. or i.t. with EM-1, EM-2, or vehicle; and tail-flick responses were then measured at different times after injection. The data were expressed as "percent maximum possible effect (\%MPE)", which was calculated as $\left.\left[\mathrm{T}_{1}-\mathrm{T}_{0}\right) /\left(\mathrm{T}_{2}-\mathrm{T}_{0}\right)\right]$ $\times 100 . \mathrm{T}_{0}$ and $\mathrm{T}_{1}$ were pre-drug and post-drug latency, respectively, and $\mathrm{T}_{2}$ was the cutoff time that was set at $10 \mathrm{~s}$ to minimize tissue damage.

\section{Protocols for drug administration}

The neurotoxins, 6-OHDA $(20 \mu \mathrm{g})$ and 5,7-DHT $(50 \mu \mathrm{g})$, were injected i.t. to degenerate noradrenergic and serotonergic terminals in the spinal cord. Mice pretreated with 5,7-DHT were also injected intraperitoneally (i.p.) with $25 \mathrm{mg} / \mathrm{kg}$ of desipramine. The use of desipramine is to block the non-specific uptake of 5,7-DHT into noradrenergic terminals (25). The i.c.v. injection $(4 \mu \mathrm{l})$ was performed according to the procedure described by Haley and McCormick (26), and i.t. injection $(5 \mu \mathrm{l})$ was performed according to the procedure of Hylden and Wilcox (27) using a 25- $\mu$ l Hamilton syringe with a 30 -gauge needle.

Two sets of experiments were designed to determine the role of spinopetal noradrenergic and serotonergic systems in antinociception induced by EM-1 or EM-2 given supraspinally or spinally. Groups of mice were pretreated i.t. with 6-OHDA, 5,7-DHT with desipramine, or vehicle 3 days prior to i.c.v. or i.t. second injection of various doses of EM-1 or EM-2; and the tail-flick test was performed at 2.5, 5, 7.5, 10, 15, and $20 \mathrm{~min}$ thereafter. Mice were then sacrificed immediately after the antinociceptive tests and the spinal cord excised for measuring the contents of NA and 5-HT. To establish dose-response curves, at least four doses were used with 8 to 15 mice at each dose. For the calculation of the $\mathrm{ED}_{50}$ values for EM-1- and EM-2-induced tail-flick inhibition, the antinociception was assessed using the peak effect, which occurred at either 2.5 or 5 min after injection.

\section{Neurochemical analysis}

Mice were killed by decapitation. A cut was made at the lumbar spine region. The spinal cord was then quickly pushed out by inserting a pipette tip connected to a $10-\mathrm{ml}$ glass syringe prefilled with cold saline into the 
lumbar end of the spinal cord. The spinal cord containing thoracic and lumbar regions was weighed and homogenized in $0.2 \mathrm{M}$ perchloric acid solution, which also contains $100 \mu \mathrm{M}$ EDTA (ethylenediaminetetraacetic acid) $(1 \mathrm{ml} / 200 \mathrm{mg}$ of spinal tissue). The sample was centrifuged at $20,000 \times g$ for $15 \mathrm{~min}$ at $0^{\circ} \mathrm{C}$. The clear supernatant was filtered using $0.45-\mu \mathrm{m}$ membrane filters for the assay of monoamines. The contents of noradrenaline and 5-HT in the spinal extract were determined by HPLC-ECD (high performance liquid chromatograph-electrochemical detector) methods as described by Sasa and Blank (28) and Ishikawa and McGaugh (29). A 10- $\mu 1$ sample solution was injected onto a reverse-phase column $\left(\mathrm{C}_{18}, 5 \mu \mathrm{m}, 3.0 \mathrm{~mm}\right.$ inside diameter $\times 150 \mathrm{~mm}$ ) with a guard pre-column having an amperometric detector (Eicom, Kyoto). The mobile phase $(0.5 \mathrm{ml} / \mathrm{min})$ was $15 \%(\mathrm{v} / \mathrm{v})$ methanol containing $50 \mathrm{mM}$ sodium acetate, $35 \mathrm{mM}$ citric acid, $0.74 \mathrm{mM} 1-$ octanesulfonic acid, and 13.4 $\mu \mathrm{M}$ EDTA.

\section{Statistical analyses}

The data were expressed as the mean with S.E.M. The maximal \%MPE was used to graph dose-response curves for EM-1 and EM-2. A two-way ANOVA followed by Bonferroni test was used to indicate the significance among groups for the time course of
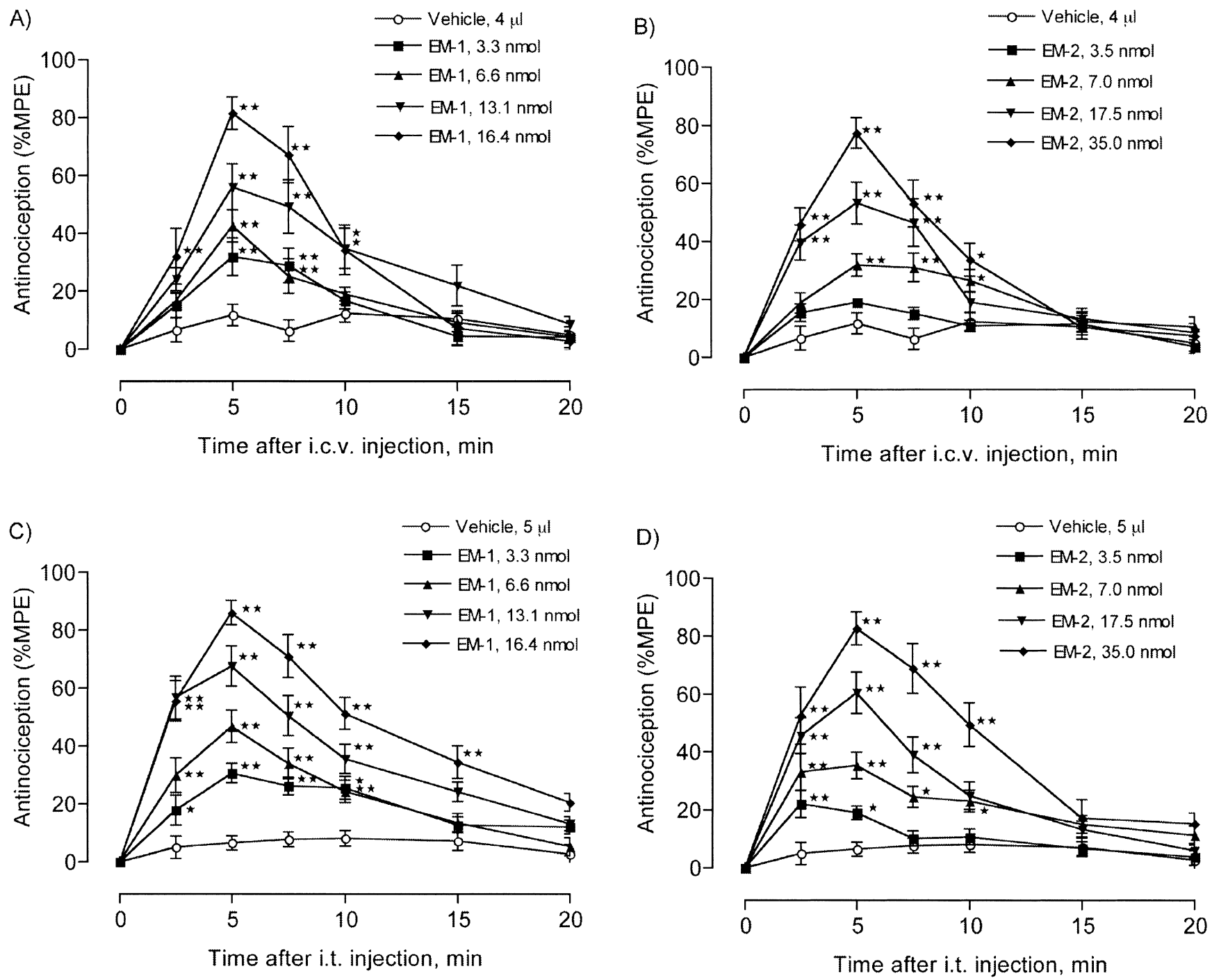

Fig. 1. Time course of changes in the tail-flick inhibition induced by i.c.v.-injected endomorphin-1 (EM-1, A) and endomorphin-2 (EM-2, B) and i.t.-injected EM-1 (C) and EM-2 (D). Groups of mice were injected i.t. with vehicle (5 $\mu$ l) for 3 days and then i.c.v.- or i.t.-injected with different doses of EM-1, EM-2, or vehicle given i.c.v. $(4 \mu \mathrm{l})$ or i.t. $(5 \mu \mathrm{l})$, and tail-flick responses were measured at different times after injection. Each value represents the mean \pm S.E.M. with 10 to 16 mice per group. A two-way ANOVA followed by Bonferroni test was used to test the difference among groups. ${ }^{*} P<0.05,{ }^{* *} P<0.01$ compared with the vehicle-treated group. 

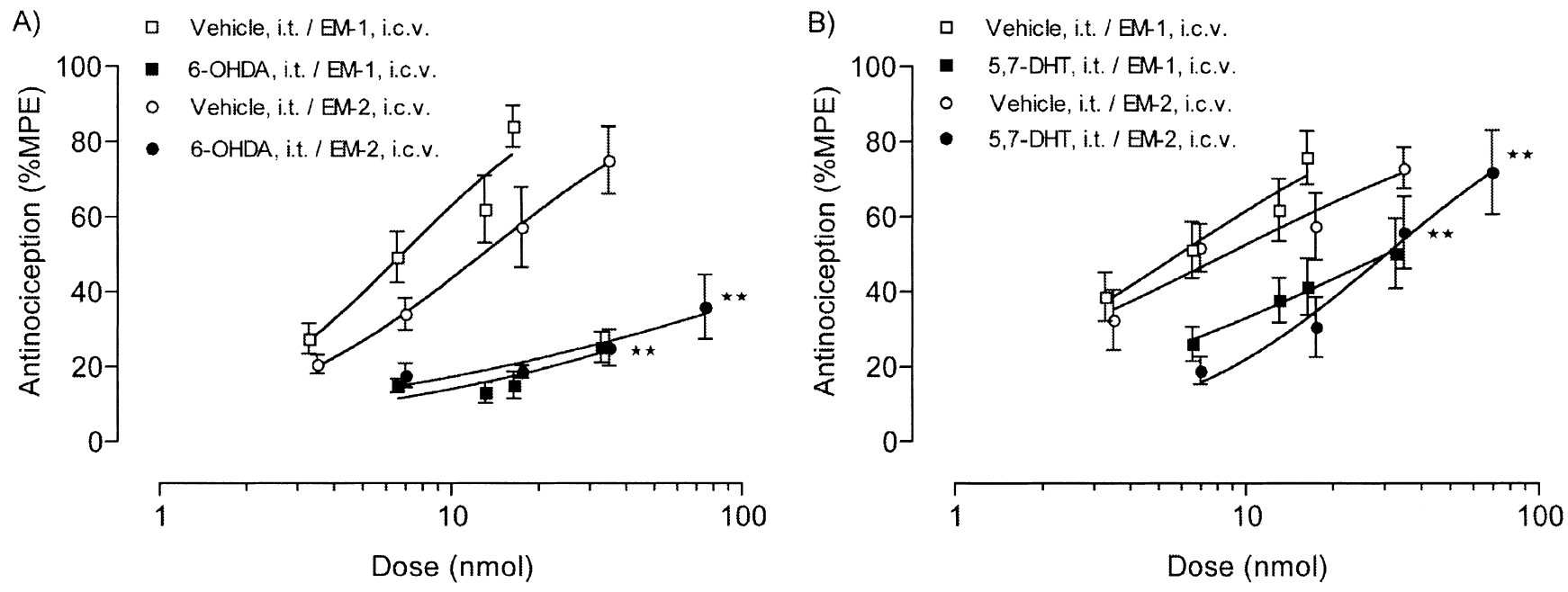

Fig. 2. Effects of i.t. pretreatment with 6-OHDA (A) and 5,7-DHT (B) on dose-response curves for the inhibition of the tailflick response induced by i.c.v. administered endomorphin-1 (EM-1) or endomorphin-2 (EM-2). Groups of mice were pretreated with vehicle or $20 \mu \mathrm{g}$ of 6-OHDA for 3 days and followed by i.c.v. injection with various doses of EM-1 or EM-2 (A). Groups of mice were pretreated i.t. with vehicle or $50 \mu \mathrm{g}$ of 5,7-DHT (after desipramine) for 3 days and then injected with various doses of EM-1 or EM-2 given i.c.v. (B). Tail-flick responses were measured. Each value represents the mean \pm S.E.M. with 8 to 13 mice per group. An F-test was used to analyze the statistical significance between dose-response curves. ${ }^{* *} P<0.01$ compared with the vehicle-pretreated group. $\mathrm{F}$ value $=73.7$ for 6-OHDA, i.t. $/ \mathrm{EM}-1$, i.c.v. vs Vehicle, i.t. $/ \mathrm{EM}-1$, i.c.v.; $\mathrm{F}$ value $=30.9$ for 6-OHDA, i.t. / EM-2, i.c.v. vs Vehicle, i.t. / EM-2, i.c.v.; F value $=13.2$ for 5,7-DHT, i.t. / EM-1, i.c.v. vs Vehicle, i.t. / EM-1, i.c.v.; F value $=9.2$ for 5,7-DHT, i.t. $/$ EM-2, i.c.v. $v s$ Vehicle, i.t. $/$ EM-2, i.c.v.

Table 1. Effects of i.t. pretreatment with $20 \mu \mathrm{g}$ of 6-OHDA and $50 \mu \mathrm{g}$ of 5,7-DHT (after desipramine) on $\mathrm{ED}_{50}$ values for EM-1 and EM-2 given i.c.v. on the inhibition of the tail-flick response

\begin{tabular}{lcc}
\hline i.t./i.c.v. & $\mathrm{ED}_{50}(95 \% \mathrm{CI}) \mathrm{nmol}$ & $\begin{array}{c}\text { Ratio } \\
\text { (treatment/vehicle) }\end{array}$ \\
\hline Vehicle/EM-1 & $6.8(5.4-8.7)$ & \\
6-OHDA/EM-1 & $>280$ & $>20$ \\
Vehicle/EM-2 & $12.9(9.1-18.3)$ & \\
6-OHDA/EM-2 & $>280$ & $>20$ \\
Vehicle/EM-1 & $5.9(3.9-9.0)$ & \\
5,7-DHT/EM-1 & $30.6(14.8-63.4)$ & 5.2 \\
Vehicle/EM-2 & $8.7(5.4-14.1)$ & \\
5,7-DHT/EM-2 & $30.6(21.3-43.9)$ & 3.5 \\
\hline
\end{tabular}

${ }^{a}$ Groups of mice were pretreated with vehicle, 6-OHDA, or 5,7-DHT given i.t. for 3 days followed by a second injection with endomorphin-1 (EM-1) or endomorphin-2 (EM-2) given i.c.v.

changes. GraphPad Prism software (version 3.0; GraphPad Software, San Diego, CA, USA) was used to calculate dose-response curves, $\mathrm{ED}_{50}$ values, and their confidence intervals. An F-test was used to analyze the significance of differences between dose response curves. A one-way ANOVA followed by Bonferroni test was used to determine the significance of the difference in spinal biogenic concentrations between the vehicle-pretreated group and neurotoxin-pretreated group.

\section{Results}

Effects of i.t. pretreatment with 6-OHDA or 5,7-DHT on the tail-flick inhibition induced by i.c.v.-administered EM-1 or EM-2

I.c.v. injection of EM-1 at doses of $3.3-16.4 \mathrm{nmol}$ (Figs. 1A, 2A, and 2B) and EM-2 at doses of $3.5-$ $35 \mathrm{nmol}$ (Figs. 1B, 2A and 2B) dose-dependently produced the inhibition of the tail-flick response in mice pretreated i.t. with vehicle. The inhibition of the tailflick response induced by EM-1 and EM-2 developed rapidly, reached their peaks at $5 \mathrm{~min}$, declined rapidly, and returned to the pre-injection level in $20 \mathrm{~min}$. A dose of $16.4 \mathrm{nmol}$ of EM-1 or $35 \mathrm{nmol}$ of EM-2 produced about $80 \% \mathrm{MPE}$ at $5 \mathrm{~min}$ after injection. I.t. pretreatment with 6-OHDA completely abolished the tail-flick inhibition induced by EM-1 and EM-2. EM-1 or EM-2 even at high doses failed to produce any tailflick inhibition (Fig. 2A). Likewise, i.t. pretreatment with 5,7-DHT also caused a marked attenuation of the tail-flick inhibition induced by EM-1 or EM-2, and the dose-response curves for EM-1 and EM-2 to inhibit the tail-flick response were shifted to the right by 5.2 - and 3.5-fold, respectively (Fig. 2B, Table 1). I.t. pretreatment with 6-OHDA and 5,7-DHT did not alter the base line tail-flick latencies in mice injected with saline; the-tail-flick latencies measured $5 \mathrm{~min}$ after i.c.v. injection of saline in mice pretreated with vehicle, 6-OHDA, 

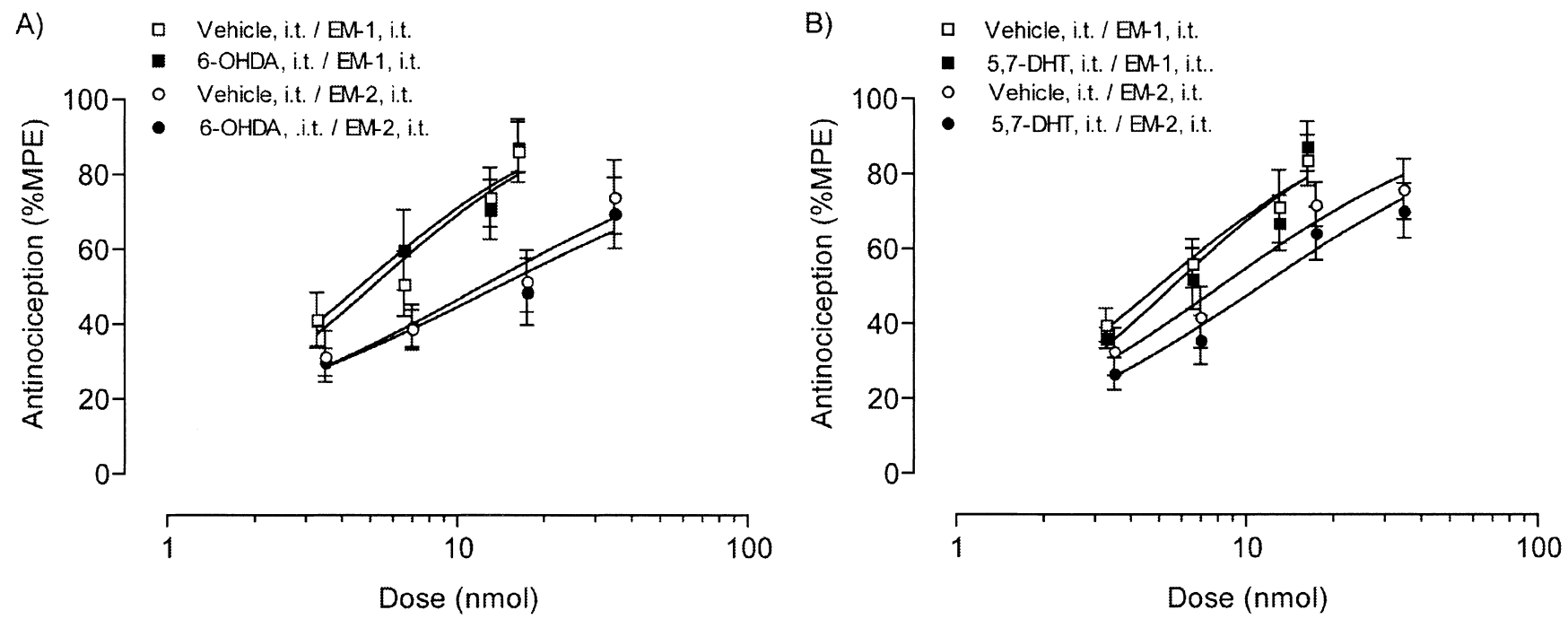

Fig. 3. Effects of i.t. treatment with 6-OHDA (A) and 5,7-DHT (B) on dose-response curves for the inhibition of the tail-flick response induced by i.t.-administered endomorphin-1 (EM-1) or endomorphin-2 (EM-2). Groups of mice were pretreated with vehicle or $20 \mu \mathrm{g}$ of 6-OHDA for 3 days and followed by i.t. injection with various doses of EM-1 or EM-2 (A). Groups of mice were pretreated i.t. with vehicle or $50 \mu \mathrm{g}$ of 5,7-DHT (after desipramine) for 3 days and then injected with various doses of EM-1 or EM-2 given i.t. (B). Tail-flick responses were measured. Each value represents the mean \pm S.E.M. with 8 to 15 mice per group. An F-test was used to analyze the statistical significance between dose-response curves. $\mathrm{F}$ value $=0.07$ for 6-OHDA, i.t. / EM-1, i.c.v. $v s$ Vehicle, i.t. / EM-1, i.c.v.; F value $=0.1$ for 6-OHDA, i.t. / EM-2, i.t. vs Vehicle, i.t. / EM-2, i.t.; $\mathrm{F}$ value $=0.16$ for 5,7 -DHT, i.t. $/ \mathrm{EM}-1$, i.t. $v s$ Vehicle, i.t. $/ \mathrm{EM}-1$, i.t.; $\mathrm{F}$ value $=0.9$ for 5,7-DHT, i.t. / EM-2, i.t. vs Vehicle, i.t. / EM-2, i.t.

Table 2. Effects of i.t. pretreatment with $20 \mu \mathrm{g}$ of 6-OHDA and $50 \mu \mathrm{g}$ of 5,7-DHT (after desipramine) on $\mathrm{ED}_{50}$ values for EM-1 and EM-2 given i.t. on the inhibition of the tail-flick response

\begin{tabular}{lcc}
\hline i.t./i.t. ${ }^{\mathrm{a}}$ & $\mathrm{ED}_{50}(95 \% \mathrm{CI}) \mathrm{nmol}$ & $\begin{array}{c}\text { Ratio } \\
\text { (treatment/vehicle) }\end{array}$ \\
\hline Vehicle/EM-1 & $5.1(3.5-7.3)$ & \\
6-OHDA/EM-1 & $4.6(3.1-6.9)$ & 0.9 \\
Vehicle/EM-2 & $12.1(7.7-19.0)$ & \\
6-OHDA/EM-2 & $13.8(8.5-22.5)$ & 1.1 \\
\hline Vehicle/EM-1 & $5.0(3.6-7.0)$ & \\
5,7-DHT/EM-1 & $5.6(4.3-7.3)$ & 1.1 \\
Vehicle/EM-2 & $8.2(5.7-11.8)$ & \\
5,7-DHT/EM-2 & $11.2(7.9-15.9)$ & 1.4 \\
\hline
\end{tabular}

${ }^{\mathrm{a}}$ Groups of mice were pretreated with vehicle, 6-OHDA, or 5,7-DHT given i.t. for 3 days followed by a second injection with endomorphin-1 (EM-1) or endomorphin-2 (EM-2) given i.t.

vehicle with desipramine, and 5,7-DHT with desipramine were $3.3 \pm 0.05,3.3 \pm 0.07,3.3 \pm 0.08$, and $3.2 \pm 0.06 \mathrm{~s}$ ( $\mathrm{n}=40$ for each group), respectively.

Effects of i.t. pretreatment with 6-OHDA or 5,7-DHT on the tail-flick inhibition induced by i.t.-administered EM-1 or EM-2

I.t. injection of EM-1 at doses of $3.3-16.4 \mathrm{nmol}$ and EM-2 at doses of $3.5-35.0 \mathrm{nmol}$ dose-dependently produced the inhibition of the tail-flick response in mice pretreated i.t. with vehicle. The inhibition of the tail-flick response induced by EM-1 and EM-2 developed rapidly, reached their peaks at $5 \mathrm{~min}$, declined rapidly, and returned to the pre-injection level in $20 \mathrm{~min}$. A dose of $16.4 \mathrm{nmol}$ of EM-1 or $35 \mathrm{nmol}$ of EM-2 produced about $80 \% \mathrm{MPE}$ at $5 \mathrm{~min}$ after injection (Fig. 1: C and D). I.t. pretreatment with 6-OHDA or 5,7-DHT did not affect the tail-flick inhibition induced by i.t.-administered EM-1 or EM-2 (Fig. 3: A and B). The $\mathrm{ED}_{50}$ values for EM-1 and EM-2 to inhibit the tail-flick response were not changed in mice pretreated i.t. with 6-OHDA or 5,7-DHT (Table 2).

Effects of i.t. pretreatment with 6-OHDA and 5,7-DHT on NA and 5-HT contents in the spinal cord

Acute i.c.v. injection of EM-1 (3.3 to $16.4 \mathrm{nmol})$ or EM-2 (3.5 to $70 \mathrm{nmol})$ even at high doses did not cause any significant change of the steady state level of NA or 5-HT of the spinal cord in mice pretreated with vehicle for 3 days. Compared to vehicle-pretreated mice, i.t. pretreatment with 6-OHDA markedly depleted NA contents in the spinal cord by more than $90 \%$, but did not cause any change of 5-HT contents of the spinal cord in mice acutely injected with different doses of EM-1 and EM-2 (Table 3). I.t. pretreatment with 5,7DHT with desipramine for 3 days markedly reduced 5- 
Table 3. Effects of i.t. pretreatment with vehicle or $20 \mu \mathrm{g}$ of 6-OHDA on spinal biogenic amine concentrations in mice 3 days before treated with i.c.v. vehicle, EM-1, or EM-2 at various concentrations

\begin{tabular}{|c|c|c|c|}
\hline \multirow[b]{2}{*}{ i.t./i.c.v. ${ }^{a}$} & & \multicolumn{2}{|c|}{ Spinal biogenic amine concentration (ng/g) } \\
\hline & & NA & $5-\mathrm{HT}$ \\
\hline Vehicle/Vehicle & & $556 \pm 35.4$ & $1195 \pm 51.9$ \\
\hline \multirow[t]{3}{*}{ Vehicle/EM-1 } & $6.6 \mathrm{nmol}$ & $544 \pm 27.0$ & $1027 \pm 42.6$ \\
\hline & $13.1 \mathrm{nmol}$ & $555 \pm 36.5$ & $1117 \pm 78.2$ \\
\hline & $16.4 \mathrm{nmol}$ & $540 \pm 51.2$ & $1100 \pm 97.4$ \\
\hline \multirow[t]{3}{*}{ 6-OHDA/EM-1 } & $6.6 \mathrm{nmol}$ & $51.4 \pm 13.7 * * *$ & $1184 \pm 85.5$ \\
\hline & $13.1 \mathrm{nmol}$ & $30.0 \pm 5.3^{* * *}$ & $1088 \pm 64.0$ \\
\hline & $16.4 \mathrm{nmol}$ & $44.9 \pm 15.2 * * *$ & $1104 \pm 54.1$ \\
\hline \multirow[t]{3}{*}{ Vehicle/EM-2 } & $7.0 \mathrm{nmol}$ & $508 \pm 64.5$ & $1156 \pm 82.0$ \\
\hline & $17.5 \mathrm{nmol}$ & $515 \pm 45.0$ & $1078 \pm 91.5$ \\
\hline & $35.0 \mathrm{nmol}$ & $571 \pm 49.9$ & $1050 \pm 44.0$ \\
\hline \multirow[t]{3}{*}{ 6-OHDA/EM-2 } & $7.0 \mathrm{nmol}$ & $69.8 \pm 12.3 * * *$ & $1077 \pm 58.3$ \\
\hline & $17.5 \mathrm{nmol}$ & $45.3 \pm 11.3 * * *$ & $1054 \pm 40.4$ \\
\hline & $35.0 \mathrm{nmol}$ & $44.7 \pm 12.0 * * *$ & $1113 \pm 32.8$ \\
\hline
\end{tabular}

${ }^{\mathrm{a}}$ Groups of mice were pretreated with vehicle or 6-OHDA given i.t. for 3 days followed by a second injection with vehicle, endomorphin-1 (EM-1), or endomorphin-2 (EM-2) given i.c.v. Each value represents the mean \pm S.E.M. with 8 to 15 mice. ${ }^{* * *} P<0.001$, compared with the vehicle/EM group, by one-way ANOVA followed by Bonferroni test.

Table 4. Effects of i.t. pretreatment with vehicle or $50 \mu \mathrm{g}$ of 5,7-DHT (after desipramine) on spinal biogenic amine concentrations in mice treated with i.c.v. EM-1 or EM-2 at various concentrations

\begin{tabular}{|c|c|c|c|}
\hline \multirow[b]{2}{*}{ i.t./i.c.v. ${ }^{a}$} & & \multicolumn{2}{|c|}{ Spinal biogenic amine concentration $(\mathrm{ng} / \mathrm{g})$} \\
\hline & & NA & $5-\mathrm{HT}$ \\
\hline Vehicle/Vehicle & & $556 \pm 35.4$ & $1195 \pm 51.9$ \\
\hline \multirow[t]{3}{*}{ Vehicle/EM-1 } & $6.6 \mathrm{nmol}$ & $463 \pm 43.5$ & $1011 \pm 41.1$ \\
\hline & $13.1 \mathrm{nmol}$ & $538 \pm 18.1$ & $1226 \pm 63.3$ \\
\hline & $16.4 \mathrm{nmol}$ & $523 \pm 29.7$ & $1085 \pm 38.0$ \\
\hline \multirow[t]{3}{*}{ 5,7-DHT/EM-1 } & $6.6 \mathrm{nmol}$ & $360 \pm 28.8$ & $79.4 \pm 17.5^{* * *}$ \\
\hline & $13.1 \mathrm{nmol}$ & $431 \pm 36.6$ & $90.6 \pm 18.8 * * *$ \\
\hline & $16.4 \mathrm{nmol}$ & $402 \pm 24.5$ & $70.1 \pm 13.7 * * *$ \\
\hline \multirow[t]{3}{*}{ Vehicle/EM-2 } & $7.0 \mathrm{nmol}$ & $489 \pm 41.1$ & $1160 \pm 50.2$ \\
\hline & $17.5 \mathrm{nmol}$ & $579 \pm 39.9$ & $1237 \pm 74.8$ \\
\hline & $35.0 \mathrm{nmol}$ & $532 \pm 40.8$ & $1042 \pm 29.4$ \\
\hline \multirow[t]{3}{*}{ 5,7-DHT/EM-2 } & $7.0 \mathrm{nmol}$ & $423 \pm 28.3$ & $103.4 \pm 18.9^{* * *}$ \\
\hline & $17.5 \mathrm{nmol}$ & $399 \pm 26.0^{*}$ & $85.8 \pm 13.6^{* * *}$ \\
\hline & $35.0 \mathrm{nmol}$ & $430 \pm 46.6$ & $113.4 \pm 16.0^{* * *}$ \\
\hline
\end{tabular}

${ }^{\mathrm{a}}$ Groups of mice were pretreated with vehicle or 5,7-DHT given i.t. for 3 days followed by a second injection with vehicle, endomorphin-1 (EM-1) or endomorphin-2 (EM-2) given i.c.v. Each value represents the mean \pm S.E.M. with 8 to 12 mice. ${ }^{*} P<0.05,{ }^{*} * P<0.001$, compared with the vehicle/EM group, by one-way ANOVA followed by Bonferroni test.

HT contents in the spinal cord by more than $92 \%$ in mice acutely injected with different doses of EM-1 or EM-2, while NA contents in the spinal cord was only reduced by $14 \%$ to $25 \%$ (Table 4 ).

\section{Discussion}

EM-1 at doses of 3.3 to $16.4 \mathrm{nmol}$ or EM-2 at doses of 3.5 to $35.0 \mathrm{nmol}$ given supraspinally or spinally dosedependently induced the antinociception with the tail- 
flick test in mice pretreated with vehicle. The results of the present studies in time course and the potencies are consistent with our previous findings $(30,31)$.

EM-1 and EM-2 are two endogenous opioid receptor ligands for $\mu$-opioid receptors (1). The antinociceptive effects induced by EM-1 or EM-2 given supraspinally by i.c.v. administration are mediated by the stimulation of $\mu$-opioid receptors. This view is evidenced by the findings that the antinociception induced by EM-1 or EM-2 is selectively blocked by the pretreatment with the $\mu$-opioid receptor antagonists, naloxone, $\beta$-funaltrexamine, or CTOP $(4,8,14,16,17)$.

It has been well documented that the antinociception with the tail-flick test induced by other $\mu$-opioid agonists such as morphine or DAMGO given supraspinally is mediated by the activation of spinopetal noradrenergic and serotonergic systems and involve the releases of noradrenaline and 5-HT acting on $\alpha_{2}$-adrenoceptors and 5-HT receptors, respectively, in the spinal cord (3234). This view is supported by the finding that i.t. pretreatment with 6-OHDA or DSP-4 ( $N$-(2-chloroethyl)$N$-ethyl-2-bromobenzylamine) to deplete noradrenaline or i.t. pretreatment with 5,7-DHT to deplete 5-HT effectively attenuates the antinociception induced by morphine given supraspinally $(20-22)$. Also the blockade of $\alpha_{2}$-adrenoceptors and 5-HT receptors by i.t. treatment with the $\alpha_{2}$-adrenoceptor blocker yohimbine and 5-HT receptor blocker methysergide effectively blocks the antinociception induced by morphine given supraspinally $(23,32,34)$. Since EM-1 and EM-2 are two selective endogenous opioid ligands of the $\mu$ type, the neural mechanisms for the production of antinociception will be expected to be the same as that of other $\mu$-opioid agonists such as morphine or DAMGO. We found in the present studies that i.t. pretreatment with 6-OHDA for 3 days, which effectively depleted NA by more than $90 \%$, but not $5-\mathrm{HT}$, completely abolished the antinociception induced by i.c.v.-administered EM-1 or EM-2. The result strongly indicates that the release of NA in the spinal cord plays an essential role in the inhibition of the tail-inhibition induced by supraspinally administered EM-1 and EM-2. I.t. pretreatment with 5,7-DHT for 3 days, which depleted 5-HT by more than $92 \%$, but also reduced NA by $14 \%$ to $25 \%$, attenuated the antinociception induced by i.c.v. administration of EM-1 or EM-2 by 5.2- or 3.5-fold. The results of our study indicate that the spinopetal noradrenergic pathway is more important than the serotonergic pathway in mediating the antinociception activated by supraspinally-administered EM-1 and EM-2. However, 5-HT in the spinal cord may also be involved in the tail-flick inhibition induced by supraspinally administered EM-1 and EM-2. We have previously demonstrated that the blockade of either $\alpha_{2}$-adrenoceptors by i.t. treatment with yohimbine or 5-HT receptors by i.t. pretreatment with methysergide effectively blocks the antinociception induced by i.c.v.-administered EM-1 or EM-2 (30). More studies are needed to determine the relative importance of these two pathways in the spinal cord involved in supraspinally-administered EM-1 and EM-2-induced antinociception.

In addition to the monoaminergic descending pain control systems, which are activated by EM-1 and EM-2, we have previously reported that two additional opioidergic pathways are also involved in antinociception induced by supraspinally-administered EM-2, but not EM-1 (17). This antinociception activated by EM-2 supraspinally is mediated in part by the release of Metenkephalin and dynorphin A(1 - 17) acting on DOP2-R and KOP-R, respectively, in the spinal cord. Since we found in the present study that depletion of noradrenaline and 5-HT by 6-OHDA and 5,7-DHT pretreatment, respectively, completely abolished the antinociception induced by EM-2 given supraspinally, it is most likely that these additional opioidergic pathways play a minor role in the overall supraspinal EM-2-induced antinociception.

Like the other $\mu$-opioid receptor agonists morphine or DAMGO, EM-1 or EM-2 given spinally produces its antinociception by direct stimulation of $\mu$-opioid receptors located on the dorsal horn of the spinal cord. This view is supported by the finding that the antinociception induced by i.t.-administered EM-1 or EM-2 is blocked by the i.t. pretreatment with $\mu$-opioid receptor antagonist $\beta$-funaltrexamine or CTOP (31). We found in the present studies that the same i.t. pretreatment with 6-OHDA or 5,7-DHT did not affect the antinociception induced by i.t.-administered EM-1 and EM-2. The result clearly indicates that NA and 5-HT in the spinal cord are not involved in the antinociception induced by spinallyadministered EM-1 and EM-2.

It is concluded that EM-1 and EM-2 given supraspinally activate spinopetal noradrenergic and serotonergic systems and release NA and 5-HT in the spinal cord for the production of antinociception. On the other hand, NA and 5-HT in the spinal cord are not involved in the antinociception induced by spinally administered EM-1 and EM-2.

\section{Acknowledgment}

This work was supported in part by Grant DA 03811 from the National Institute of Health, National Institute on Drug Abuse (PI: L.F.T.). 


\section{References}

1 Zadina JE, Hackler L, Ge L-J, Kastin AJ. A potent and selective endogenous agonist for the $\mu$-opiate receptor. Nature (Lond). 1997;386:499-502.

2 Hackler L, Zadina JE, GE LJ, Kastin AJ. Isolation of relatively large amounts of endomorphin-1 and endomorphin-2 from human brain cortex. Peptide. 1997;18:1635-1639.

3 Dun NJ, Dun SL, Wu SY, Williams CA, Kwok EH. Endomorphins: localization, release and action on rat dorsal horn neurons. J Biomed Sci. 2000;7:213-220.

4 Goldberg IE, Rossi GC, Letchworth SR, et al. Pharmacological characterization of endomorphin-1 and endomorphin-2 in mouse brain. J Pharmacol Exp Ther. 1998;286:1007-1013.

5 Martin-Schild S, Gerall AA, Kastin AJ, Zadina JE. Endomorphin-2 is an endogenous opioid in primary sensory afferent fibers. Peptide. 1998;19:1783-1789.

6 Martin-Schild S, Gerall AA, Kastin AJ, Zadina JE. Differential distribution of endomorphin 1- and endomorphin 2-like immunoreactivities in the CNS of the rodent. J Comp Neurol. 1999; 405:450-471.

7 Martin-Schild S, Zadina JE, Gerall AA, Vigh S, Kastin AJ. Localization of endomorphin-2-like immunoreactivity in the rat medulla and spinal cord. Peptide. 1997;18:1641-1649.

8 Schreff M, Schulz S, Wiborny D, Hollt V. Immunofluorescent identification of endomorphin-2-containing nerve fibers and terminals in the rat brain and spinal cord. Neuroreport. 1998;9: 1031-1034.

9 Pierce TL, Grahek MD, Wessendorf MW. Immunoreactivity for endomorphin-2 occurs in primary afferents in rats and monkey. Neuroreport. 1998;9:385-389.

10 Wu SY, Dun SL, Wright MT, Chang J-K, Dun NL. Endomorphin-like immunoreativity in the rat dorsal horn and inhibition of substantia gelatiniosa neurons in vitro. Neuroscience. 1999;89:317-321

11 Chu XP, Xu NS, Li P, Wang JQ. Endomorphin-1 and endomorphin-2, endogenous ligands for the $\mu$-opioid receptor, inhibit electrical activity of rat rostral ventrolateral medulla neurons in vitro. Neuroscience. 1999;93:681-686.

12 Williams CA, Wu SY, Dun SL, Kwok EH, Dun NJ. Release of endomorphin-2 like substances from the rat spinal cord. Neurosci Lett. 1999;273:25-28.

13 Mizoguchi H, Narita M, Oji DE, et al. $\mu$-Opioid receptor gene-dose dependent reductions in G-protein activation in the pons/medulla and antinociception induced by endomorphins in $\mu$-opioid receptor knockout mice. Neuroscience. 1999;94:203207.

14 Stone LS, Fairbanks CA, Laughlin TM, et al. Spinal analgesia actions of the new endogenous opioid peptides endomorphin-1 and -2. Neuroreport. 1997;8:3131-3135.

15 Narita M, Mizoguchi H, Oji GS, et al. Characterization of endomorphin-1 and -2 on $\left[{ }^{35} \mathrm{~S}\right] \mathrm{GTP} \gamma \mathrm{S}$ binding in the mouse spinal cord. Eur J Pharmacol. 1998;351:383-387.

16 Tseng LF, Narita M, Suganuma C, et al. Differential antinociceptive effects of endomorphin- 1 and endomorphin-2 in the mouse. J Pharmacol Exp Ther. 2000;292:576-583.

17 Tseng LF. The antinociceptive properties of endomorphin-1 and endomorphin-2 in the mouse. Jpn J Pharmacol. 2002;89:216220.
18 Mizoguchi H, Tseng LF, Suzuki T, Sora I, Narita M. Differential mechanism of G-protein activation induced by endogenous $\mu$ opioid peptides, endomorphin and $\beta$-endomorphin. Jpn J Pharmaol. 2002;89:229-234.

19 Zhong FX, JI XQ, Tsou K. Intrathecal DSP-4 selectively depletes spinal noradrenaline and attenuates morphine analgesia. Eur J Pharmacol. 1985;116:327-330.

20 Rodriguez FD, Rodriguez RE. Intrathecal administration of 5,6DHT or 5,7-DHT reduced morphine and substance $\mathrm{P}$ antinociceptive activity in the rat. Neuropeptides. 1989;13:139-146.

21 Sawynok J, Reid A, Nance D. Spinal antinociception by adenosine analogs and morphine after intrathecal administration of the neurotoxins capsaicin, 6-hydroxydopamine and 5,7dihydroxytryptamine. J Pharmacol Exp Ther. 1991;258:370379.

22 Suh HH, Hong JJ-S, Tseng LF. Intrathecial DSP-4,6-hydroxydopamine and 5,7-dihydroxytryptamine differentiate intracerebroventricular $\beta$-endorphin- from morphine-induced antinociception in the mouse. Pharmacol Commun. 1992;1:227232.

23 Suh HH, Fujimoto JM, Tseng LF. Differential mechanisms mediating $\beta$-endorphin- and morphine-induced analgesia in mice. Eur J Pharmacol. 1989;168:61-79.

24 D'Amour FE, Smith DL. A method for determining loss of pain sensation. J Pharmacol Exp Ther. 1941;72:74-79.

25 Björklund A, Baumgarten HG, Rensch A. 5,7-Dihydroxytryptamine: Improvement of its selectivity for serotonin neurons in the CNS by pretreatment with desipramine. J Neuchem. $1975 ; 24: 833-835$.

26 Haley TJ, McCormick WG. Pharmacological effects produced by intracerebral injection of drugs in the conscious mouse. $\mathrm{Br} \mathrm{J}$ Pharmacol. 1957;12:12-15.

27 Hylden JLK, Wilcox GL. Intrathecal morphine in mice: a new technique. Eur J Pharmacol. 1980;167:313-316.

28 Sasa S, Blank CL. Determination of serotonin and dopamine in mouse brain tissue by high performance liquid chromatography with electrochemical detection. Anal Chem. 1977;49:354-359.

29 Ishikawa K, McGaugh JL. Simultaneous determination of monoamine transmitters, precursors and metabolites in a single mouse brain. J Chromatography. 1982;229:35-46.

30 Ohsawa M, Mizoguchi H, Narita M, Chu M, Nagase H, Tseng LF. Differential mechanisms mediating descending pain controls for antinociception induced by supraspinally-administered endomorphin-1 and endomorphin-2 in the mouse. J Pharmacol Exp Ther. 2000;294:1106-1111.

31 Ohsawa M, Mizoguchi H, Narita M, Nagase H, Kampine JP, Tseng LF. Differential antinociception induced by spinally administered endomorphin-1 and endomorphin- 2 in the mouse. J Pharmacol Exp Ther. 2001;298:592-597.

32 Jensen TS, Yaksh TL. Examination of spinal monoamine receptors through which brainstem opiate-sensitive systems act in the rat. Brain Res. 1986;363:114-127.

33 Tseng LF, Tang R. Differential mechanisms mediate $\beta$ endorphin- and morphine-induced inhibition of the tail-flick response in rats. J Pharmacol Exp Ther. 1990;252:546-551.

34 Tseng LF, Collins KA. Differential mechanisms mediating tailflick inhibition induced by $\beta$-endorphin, DAMGO and morphine from Rob and GiA in anesthstized rat. J Pharmacol Exp Ther. 1991;257:530-538. 